\title{
Piracy and New Product Creation: A Bollywood Story ${ }^{1}$
}

\author{
Rahul Telang, Carnegie Mellon University \\ Joel Waldfogel, University of Minnesota and NBER \\ (rtelang@andrew.cmu.edu; jwaldfog@umn.edu)
}

August 6, 2014

\begin{abstract}
While copyright research in the decade following Napster focused mostly on whether file sharing undermines demand, research has more recently asked how piracy and other aspects of digitization affect the supply of new products. Although revenue has declined sharply, evidence that weakened effective copyright protection undermines creation has been elusive. Instead, because of cost-reducing effects of digitization, the number of new recorded music products - and their apparent quality - has increased. This study examines movie production in India during a period of technological change that facilitated large-scale piracy. The diffusion of the VCR and cable television in India between 1985 and 2000 created substantial opportunities for unpaid movie consumption. We use this episode to study possible impacts of piracy on supply. We first document, from narrative sources, conditions conducive to piracy as these technologies diffused. We then provide strong circumstantial evidence of piracy in diminished appropriability: movies' revenues fell by a third to a half, conditional on their ratings by movie-goers and their ranks in their annual revenue distributions. Weaker effective demand undermined creative incentives. While the number of new movies released had grown steadily from 1960 to 1985, it fell markedly between 1985 and 2000, suggesting a supply elasticity in the range of 0.2-0.7. Thus, our study provides affirmative evidence on a central tenet of copyright policy, that stronger effective copyright protection effects more creation. We contrast our findings with evidence from other contexts.
\end{abstract}

\footnotetext{
${ }^{1}$ Rahul Telang acknowledges Uttara Ananthakrishnan's help in data collection from the censor board. Authors also thank the Indian censor board for sharing some of the data used in the analysis.
} 


\section{Introduction}

In the decade and a half since Napster, researchers have focused substantial attention on the question of whether file sharing undermines demand. Most observers now agree that the ability of consumers to obtain recorded music without paying makes it more difficult for sellers of recorded music to generate revenue. ${ }^{2}$ Industry participants are understandably concerned that shrinking revenues will hurt them, but policy makers also have cause for concern if revenue reduction prevents firms from bringing new products to market. The few available studies of the supply response in recorded music find that, despite substantial revenue reduction, the number of new products has not declined and indeed has instead increased (Handke, 2012; Oberholzer-Gee \& Strumpf, 2007; Waldfogel, 2012). Moreover, the service flow from new music appears to be strong. In short, despite the collapse of recorded music revenue, consumers appear not to have suffered. These results are counterintuitive to the essential premise of copyright.

Whether large-scale revenue reductions would leave the quantity and appeal of new products unharmed in contexts outside music is an open question. For example, movies have traditionally required substantially larger investment than music, suggesting that revenue reduction might have a larger impact on movie production. In part because the North American and European movie industries have not experienced a discrete Napster-like negative shock to revenue, we lack much direct evidence on the magnitude of the supply response to a change in appropriability. While there are anecdotal accounts of piracy's impact on small film makers' ability to produce movies ${ }^{3}$, we know of no

\footnotetext{
${ }^{2}$ See, for example, the studies summarized in Liebowitz (2011) and Danaher, Smith and Telang (2014).

${ }^{3}$ http://www.forbes.com/sites/jamesmarshallcrotty/2012/01/31/better-than-sopa-public-education-bestweapon-against-web-piracy/
} 
systematic evidence that the volume or appeal of new motion pictures has changed in response to piracy.

The paucity of empirical evidence on possible supply side effects of piracy on copyright protected industries is a longstanding problem. A recent National Research Council (NRC) report highlights lack of empirical documentation of the short run and long run effects of copyright (NRC, 2013). It also argues for the need to gather empirical evidence in forming a well-informed copyright policy in digital era. Much of the existing empirical work has looked at the effect of copyright extension on availability of the work (Buccafusco and Heald, 2012; Heald, 2013) rather than creation and production.

In this paper, we will focus on Bollywood - a popular term for the Indian motion picture industry - to study these very issues. Fortunately for the prospects of research, if not for the producers themselves, the Indian movie industry experienced a substantial shock to movie revenue during the late 1980s and 1990s with the diffusion of two new technologies. First, the appearance of the VCR facilitated widespread unauthorized movie distribution. In 1982, shortly after the VCR was introduced in the US, thenpresident of the Motion Picture Association of America Jack Valenti testified before the US Congress that "the VCR is to the American film producer and the American public as the Boston strangler is to the woman home alone.” While his concerns about the VCR as a tool for unpaid consumption did not materialize in the US, they apparently did - as detail below - in India. Second, the spread of cable television in the 1990's was accompanied by widespread unauthorized airing of new films on independent and (then) mostly unregulated cable networks. These new distribution channels undermined revenue generation following the mid-1980s. 
Following 2000, new revenue opportunities arose in the Indian film market. First, growth in shopping malls led to construction of multiplex theaters that drew audiences to the movies. Second, growth in exports of movies and licensing revenues from contenthungry domestic television channels were other significant sources appearing around 2000. The possibility of a negative shock to revenue in the mid-1980s, followed by a reversal around 2000, raises the possibility of a large, if slow-moving, "experiment” that we might use for documenting effects of intellectual property appropriability on the supply of new products.

We propose to make use of these events to examine three questions in the paper. First, did VCR and cable piracy of between 1985 and 2000 produce a negative shock to revenue, reducing the revenue available to a film with a given level of appeal? We cannot observe unpaid consumption directly, but we can ask whether movies generated less revenue, overall or conditional on revenue rank or subjective measures of "quality." Second, did movie entry respond to the effectively reduced market size? This, in turn, has two parts: did the volume of new movies change? And, third, did the quality of movies change?

The challenge we face in answering these questions is mostly the difficulty of finding suitable data, which has been a substantial barrier to studying copyright and product creation. To this end, we assemble data on movie-level and aggregate revenue for Indian movies, as well as the number of new movies released in India and other countries, from a variety of disparate sources including the Internet Movie Database (IMDb), IBOS, the Indian Film Censor Board, and the Uttar Pradesh entertainment tax office. 
Our analysis proceeds in three parts. First, we provide descriptive evidence, including contemporary accounts, that the diffusion of the VCR and independent cable television operators in the period 1985-2000 allowed consumers to watch movies without paying. Second, we use available movie-level revenue data to look for indirect evidence of an impact of piracy on appropriability. That is, we ask whether movies of a given quality generated less revenue, and we find that even after controlling for quality (as measured from IMDB ratings), revenue per movies declined by as much as $50 \%$ during the period 1985-2000. We also find, from the entertainment tax data from a particular state (Uttar Pradesh), that aggregate revenues also declined during this period. We then turn to the supply question directly, asking whether Indian movie production contracted during the period of weakened appropriability. We find that revenue reduction led to a reduction in movies produced, roughly suggesting a supply elasticity between 0.2 and 0.7 . We also provide evidence that quality of movies also declined during this period.

The paper proceeds as follows. Section 2 provides background on the Indian film industry as well as a narrative account of the impact of the VCR and independent cable operators on opportunities for unpaid consumption. Section 3 describes our data in detail. Section 4 then presents our results: first, we present evidence on reduced appropriability; second, we present evidence of a supply contraction, along with some additional evidence to demonstrate the robustness of the results. Section 5 presents some discussion of the results in international and industrial context. A brief conclusion follows. 


\section{Background: Indian Cinema and Piracy}

\subsection{Indian Cinema Industry}

Measured by the number of movies released into theaters each year, the Indian motion picture industry is - and long has been - the largest producer of movies in the world. For example, in 2006 US producers released 500 movies, while Indian producers released about 1,000. While India makes the most movies, its investment is comparatively low. According to Screen Digest, in 2010 when US producers invested \$9.2 billion on 754 movies (\$15 million per film on average), Indian producers invested \$479 million on their slate of 1,274 movies (\$0.38 million per film on average). US producers spent an average of 24 times as much per movie as their Indian counterparts. ${ }^{4}$ Even after accounting for GDP differences, these differences are substantial.

Because of India's linguistic diversity, Indian studios produce movies in a variety of languages. Hindi film, commonly termed Bollywood, is the largest component, followed closely by Tamil and Telugu. Other popular languages include Kannada and Malayalam, followed by Bengali, Marathi, and Gujarati. In revenue terms the Indian movie industry was the $6^{\text {th }}$ largest in the world in 2013 with $\$ 1.4$ billion in revenue, following the North America (\$10.8 billion), China (\$2.7), Japan (\$2.4), France (\$1.7), and the UK (\$1.7). ${ }^{5}$

The Indian movie industry began production in early twentieth century and flourished between the 1940s and the 1980s. Traditionally, audiences watched movies in "single screen" theaters, large cinema halls with more than 1,000 seats. Because a theater

\footnotetext{
${ }^{4}$ See "World film production report: stable global film production hides decline in key territories." Screen Digest Nov. 2011: 323. Expanded Academic ASAP. Web. 26 Aug. 2013.

${ }^{5}$ See "Top 10 Film Countries by Box Office." FilmContact.com 13 April

2013. http://www.filmcontact.com/americas/united-states/top-10-film-countries-box-office
} 
could only exhibit one movie at a time, and because typical movies were 2.5-3 hours long, these theaters could only play a movie 3-4 times a day. The total number of theaters reached roughly 12,500 in 1985 (Mittal 1995). Before the 1980s almost all the revenues for the industry came from domestic theatrical release. Movies were exhibited using analog prints (film), which were expensive, and sequentially released with large cities getting the prints first and then moving to smaller population centers over time

\subsection{New Technologies and Threats to Revenue:}

The VCR and Cable, 1985-2000.

While Jack Valenti erred in his prediction about the impact of the VCR on the US film industry, he may have been more accurate in this forecast about India, where the growth of VCRs led to widespread piracy.

The early 1980’s saw strong growth in Indian television penetration. The 1982 Asiad games in New Delhi brought color TV to India and spurred its diffusion (KohilKhandekar, 2013). By 1989, 23 million households, most in urban centers, had a television. With about 150 million households in India, about a third in urban centers, this represented a significant penetration of TV in urban India. Growth in the availability of VCRs accompanied the spread of television in India.

Within few years of television's diffusion, VHS rental shops emerged in many Indian cities. Most video libraries carried a large number of pirated prints for many Bollywood movies that users could rent cheaply (Study on Copyright Piracy, India 1999; referred to as the SCP study henceforth). Many video parlors functioning as defactor theaters playing pirated tapes of recent releases appeared during the 1980s. According to Mittal (1995), by the late 1980's there were about 60,000 video parlors and 
30,000 cassette libraries in India, almost all of them selling and exhibiting pirated copies of latest Indian movies. Boyd, Straubhaar, and Lent (1989) outline how even in poor or rural areas of India, VCR parlors were widely available. Given that a single VCR could serve many viewers per screening, even a low VCR penetration rate could lead to significant volumes of unpaid consumption. ${ }^{6}$

Because a typical movie in the 1980s was shown using expensive analog prints, sequential release of movies was common. Big cities saw the release of movies first, and the prints moved to smaller centers later. Delays in availability created opportunities for video parlor operators. By 1985, unauthorized distribution in video parlors was sufficiently widespread that Bollywood studios began increasing the number of prints to allow wider simultaneous release. ${ }^{7}$

While the late 1980s had brought the opportunity for video piracy, the 1990s brought cable piracy. Officially, the growth of cable commenced in 1992 when Zee Television began distribution. Within few years, many distributors (including Star, Sony TV and others) entered the Indian market offering end users multiple options. By the mid 1990s nearly 15 million homes had a cable connection, and by 1999, 40 percent of urban households had cable (Kohli-Khandekar 2010). According to the SCP study, cable penetration reached 40 percent in Mumbai, and 27 percent in Delhi and Chennai by 1997.

\footnotetext{
6 The large negative impact of the VCR on the Indian movie industry in the 1980s and 1990s is well documented in variety of trade and academic sources (Boyd, Straubhaar, Lent 1989, Alvaredo ed. 1988, O’Regan 1991, Moullier 2007). ${ }^{7}$ https://web.archive.org/web/20130115225714/http://boxofficeindia.com/showProd.php?itemCa

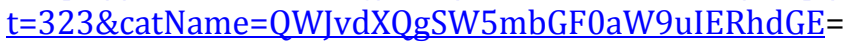


The early growth in cable distribution was accompanied by unofficial cable operators delivering high quality over-the-air TV to apartment buildings in urban India. ${ }^{8}$ By the mid 1990's, cable had penetrated significantly in urban centers and was mostly unregulated. Over 30,000 cable operators competed fiercely for customers in small neighborhoods (SCP 1999). Most carried additional local channels predominantly playing Bollywood movies rented from a video library. The SCP study, based on the interviews with cable operators, indicates that almost all operators played two or three movies per day, and almost all of these movies were unlicensed. Many were new movies playing in the nearby theaters. Users could watch a new movie at home without paying and without needing to obtain a pirated cassette or own a VCR.

Various sources confirm the significance of cable piracy. ${ }^{9}$ Some studies estimate losses due to piracy, assuming that a user watching a pirated movie would otherwise have paid the market price for that movie. While these estimates are dubious, they nevertheless confirm that cable piracy was understood to be an important issue at the time. ${ }^{10}$ The ubiquity of unpaid consumption opportunities is substantiated by an International Intellectual Property Alliance study (IIPA 2001) indicating that "there is hardly any Indian film title which is not readily available in pirate video format within a few days of its theatrical release.” The popularity of cable piracy can be gauged from the fact that pirated cable movies were adversely affecting the business of pirated rental VHS

\footnotetext{
${ }^{8}$ Kohli-Khandekar (2010) provides a fascinating account of the growth of cable and associated piracy. The use of cable avoided the use of difficult-to-manage antennas. Because the entire building was connected with a common cable, the operator could connect a VCR to broadcast unauthorized movies into apartments. Cable's early growth in India was driven largely by pirated movies played by operators. Boyd, Straubhaar and Lent (1989, page 109) presents a similar description, as does D’Souza (1991).

${ }^{9}$ See Indian Media business (2003), Screen Digest (1998), Billboard (1991), Media Piracy in Emerging Economies (2008), Bertrand Moullier (2007); and others.

${ }^{10}$ For example, the SCP study estimates that Cable Piracy costs about Rs. 936 Million worth of losses in 1997.
} 
tapes (D’Souza 1991). According to Moullier (2007), the small size of the Indian home video market (6-7 percent of revenue) is a legacy of the high level of piracy.

Out of concern that unauthorized cable broadcasts undermined legal revenue, rights holders sought legal action to curtail unpaid consumption. In 1989, the Mumbai High Court ruled that cable operators needed rights to broadcast movies (and that rented video cassettes were strictly for household consumption). Enforcement of these laws was incomplete, and the Indian movie reported continued losses. ${ }^{11}$ On July 3, 1997, the Tamil industry shut down the theaters and staged a protest rally against cable piracy (Screen Digest 1998). Bollywood producers staged a similar protest a month later, and all movie-related activities were shut down on August 11, 1997 in protest against cable piracy.

To summarize, while we do not observe the volume of unpaid movie consumption, the contemporary accounts give us reason to suspect that India experienced substantial movie piracy as television, the VCR, and cable diffused in India, 1985-2000.

\subsection{Positive Shocks to Revenues - 2000 and onwards}

The late 1990s and early 2000s witnessed a few developments with the promise of reversing the threats to revenue of the previous decade. First, piracy emerged on the policy agenda, and the government both passed more stringent laws against cable piracy and undertook stronger enforcement. The Copyright Act of 1957 was amended in 1994, and implemented in 1995, resulting in modern copyright laws for India. ${ }^{12}$ At the end of

\footnotetext{
${ }^{11}$ See Boyd, Straubhaar and Lent (1989), p. 118.

${ }_{12}$ Minimum penalty provisions (sections 63, 63A and 63B) provided for a mandatory six-month minimum jail term for commercial piracy, with a maximum term of three years, and a minimum fine of 50,000 rupees (U.S.\$1,210) and a maximum of two lakh rupees (U.S.\$4,840). The minimum jail term was doubled to one year and the minimum fine increased to one lakh rupee $(U . S . \$ 2,420)$ for a second and subsequent offense.
} 
1999, the Indian government adopted a number of further amendments intended to bring its IP laws into compliance with TRIPS. According to the IIPI (2001), the industry started using civil cases, as opposed to the rather slow criminal system, to bring injunctions against cable pirates, with some success in slowing piracy in general and cable piracy in particular.

\section{Growth of Multiplexes}

While better enforcement may have reduced piracy, another possible factor favoring revenue growth was the growth of multiplex theaters. Until the 1990's, exhibition was dominated by single-screen theaters which could accommodate large numbers of viewers but could play only one movie at a time. Most of the theaters were owned by small business owners who did not have financial resources to invest in improvements in the theatrical experience.

The quality of theaters had degraded during the 1980s and 1990s, presumably under pressure from piracy, creating a vicious cycle. ${ }^{13}$ Poor theaters made cable piracy more attractive to end users depriving theaters of money to invest. This in turn had an especially adverse effect on families and women going to theaters. The poor condition of theaters led the producer of a major 1994 family movie to deny prints to theaters in poor condition, inducing some exhibitors to improve their facilities. ${ }^{14}$

\footnotetext{
"Use" of an infringing computer program now carried a minimum jail term of seven days and a minimum fine of 50,000 rupees (U.S.\$1,210) (IIPA Report 2001).

13 "Bollywood to Protest against Cable Piracy on August 11", Rediff on the Net, July 27, 1998 (http://www.rediff.com/money/1998/jul/27film.htm).

${ }^{14} 4$ The release of Hum Aapke Hain Kaun was a defining moment in the box office history of Hindi cinema. Hum Aapke Hain was a limited release on hand picked theaters by the makers of the film and prints were only given if theaters were upgraded to a certain level. Due to unparalleled demand for the film after its release, exhibitors upgraded their theaters to get prints of the film. This resulted in ticket prices going up heavily and the family audience which rarely ventured into cinema halls at the time due to sub standard theaters came back in full force and not only did Hum Aapke Hain Kaun smash all records but took business for films released afterwards to another level.” From Boxofficeindia.com, retrieved
} 
In the late 1990s India saw substantial investments in modern shopping malls. These malls used theaters to attract patrons, leading to the growth of multiplex theaters, high-end theaters with more than 3 screens on a property but with lower seating capacities compared to single-screen theaters. ${ }^{15}$ In addition to providing a higher-quality theatrical experience (A/C, high quality sound, digital prints), these theaters also charged high prices (5-6 times higher than in single screen).

The first Indian multiplex opened in Delhi in 1997, but more substantial growth occurred in early 2000s. The government also offered significant tax breaks for new multiplexes. Today there are about 900 operational screens in multiplex theaters and about 9,000 screens in traditional single-screens theaters. While multiplexes have about a tenth of screens, they generate more than $50 \%$ of box office revenues for top 50 Hindi movies. $^{16}$

\section{Development of other Revenue Sources}

The growth of overseas markets for Indian movies, as well as the growth in domestic television licensing, produced additional revenue. The global IT boom led many young white-collar Indian professionals overseas for jobs, creating a foreign revenue opportunities. By 2005-06, almost 60 Hindi movies were released in overseas markets, and some major releases generated a third of their revenues abroad (KohliKhandekar 2010). ${ }^{17}$

at http://web.archive.org/web/20121227123801/http://www.boxofficeindia.com/showProd.php?itemCat=12 6\&catName=MTk5MC0xOTk5

${ }_{15}$ J. Anand, "Show Time.” Business Today, May 13, 2012. (see http://businesstoday.intoday.in/story/multiplex-boom-india/1/24168.html )

${ }^{16}$ See footnote 15.

${ }^{17}$ Many top Tamil and Telugu movies are released in international markets as well. 
Television also provided a new source of revenue. The Indian television market has seen growth in multichannel systems and is a Rs 300 billion industry (KohliKhandekar 2010, Table 2.1, page 56). Many channels seek movies to broadcast, and competition amongst the channels has raised the amount of revenue that movie producers can fetch for their content. A big-budget movie can generate about a quarter of its total revenues from TV licensing alone (Kohli-Khandekar 2010, page 132).

Prior to 1985 users had few options for consuming movies in unauthorized ways. Following 1985, we therefore have two relatively distinct periods with different revenue conditions. Between 1985 and 2000 the diffusion of the VCR and cable enabled widespread unpaid consumption. Around 2000, conditions for revenue generation grew more auspicious through a combination of stronger IP enforcement and the development of markets at home - in new multiplexes and on television - and abroad. We will make use of these events to ask whether revenue fell and supply contracted during the period 1985-2000, relative to the periods before and after.

\section{Data and Sources}

The study makes use of two basic datasets drawn from five distinct sources. The first dataset is a movie-level data set with the Indian box office revenue of the top 50 Hindi movies from each year, 1960-2010. The second is a country-level annual dataset with measures of movie production for various countries, including India, as well as an indirect measure of Indian total box office revenue based on entertainment tax collections.

Box office data are not as readily available for Indian movies as they are for movies from other countries. For example, as of 2014, Box Office Mojo reports data on 
movie revenue in 48 countries, but they do not report data for India. ${ }^{18}$ Older movie-level data on box office revenue are generally difficult to obtain for most countries. US box office revenue data are perhaps the best documented, and they are only available at Box Office Mojo back to $1980 .^{19}$ Against this backdrop we are fortunate to have movie-level revenue data for the top 20 Hindi-language Indian movies, 1960-2010, as well as the full top 50, 1981-2010, from IBOS. ${ }^{20}$ IBOS is a "news service geared towards providing news focusing on the business of international cinema in various Indian markets and related media metrics relevant in these territories." ${ }^{21}$ While these data cover only Hindi movies, Hindi movies earn revenues that are substantial compared to regional movies (Mittal, 1995, p. 91). We have these data for a total of 1,842 releases over 50 years.

We combine these movie-level revenues with some information from the Internet Movie Database (IMDb). IMDb provides user ratings of movies, based on a ten-point scale. We also have genre information from IMDb.

The second basic database we create is a country-by-year database with the number of movies produced by year. Finding the number of movies produced is somewhat challenging, but we have two sources of data on the number of films produced in India by year. Our first source is IMDb. These data go back to 1960 (and earlier), but the site has only existed since 1990, so it is possible that its coverage is both incomplete and, moreover, that the degree of incompleteness is higher for older movies. ${ }^{22}$ However, we expect that most well known movies are listed in this database.

\footnotetext{
18 See http://boxofficemojo.com/intl/ .

19 See http://boxofficemojo.com/yearly/chart/?yr=1980\&p=.htm .

${ }^{20}$ See http://ibosnetwork.com/default.aspx .

${ }^{21}$ See http://ibosnetwork.com/about.aspx .

${ }^{22}$ See http://en.wikipedia.org/wiki/Internet_Movie_Database .
} 
A second source of data on the number of movies produced in India is the Indian Censor Board (http://cbfcindia.gov.in/). Every film released in India has to be censor certified. We have data from the Censor Board in two forms. First, we have an aggregate time series of films processed by the Censor Board from 1971-2010. ${ }^{23}$ The aggregate data overstate production by including each dubbed version as a separate entry. For example, a Hindi movie appears once under its release language and then another time if it is dubbed into another Indian language. ${ }^{24}$ These dubbed numbers can be substantial (In 1996, out of 683 movies reported by the censor board, about 25 percent (174) movies were dubbed from one language to the other). Moreover, some movies get re-certified to protect the title or for re-release purposes. It gets counted as a new movie. Hence, the Censor Board's aggregate data overstate actual movie production in India, sometimes substantially.

Second, we were also able to obtain the movie-level data back to 1960 from the Censor Board website. The movie-level data allow us to exclude foreign movies and to count Indian movies translated from one Indian language to another only once. A shortcoming of the movie-level data, however, is that the total number of films does not match the aggregates reported by the Censor Board. While our aggregation of the movielevel data matches well with censor board data for pre 1985 and post 2000 period, it falls short of the Censor Board-reported totals for the years of keenest importance for our study, between about 1985 and 2000 .

\footnotetext{
${ }^{23}$ The same data is reported in our publications (like Screen Digest) or in websites like http://screenville.blogspot.com/p/world-cinema-stats-index.html.

${ }^{24}$ For years since 1994 the Censor Board reports an aggregate number of dubbed entries, but the resulting series does not begin early enough to be useful for our exercise. However, these data do indicate that in some years $20-25 \%$ of entries were dubbed movies.
} 
We explored this discrepancy further and learned that the Censor Board opened many regional offices (Bangalore, Trivandrum in 1984; Hyderabad in 1986; New Delhi in 1990; Cuttack in 1991; Guwahati in 1996) ${ }^{25}$ where filmmakers could file certification applications. Prior to 1984, all movies had to file for certification in the Mumbai, Chennai and Kolkata offices. After the new offices opened, some movies started getting certified at these new offices. Our micro data set includes all certifications issued by Mumbai and Chennai offices but is missing the certifications issued by the other centers during the 1980s and 1990s. For example, certifications from Hyderabad are missing until 2003. However, Mumbai and Chennai certificates are available all the way back to the 1950s.

Due to the missing data from certain centers during 80 's and 90's, aggregations from the micro data will undercount the number of movies. However, we can make use of India's regional linguistic diversity to create a production index that avoids this problem. Many regional movies apply for certificates in local center. For example, most Oriya language movies would apply for certification in Cuttack. Since the micro data are complete for Mumbai and Chennai center, we look for regional movies that always apply for certifications to these centers. Unfortunately, the Chennai center is not useful because Tamil movies not only get certifications in Chennai but also in Hyderabad and Bangalore. The micro data on certifications in Mumbai are more useful: movies in four selected language (Marathi, Gujarati, Punjabi, and Rajasthani) are always certified in Mumbai. ${ }^{26}$ Hence, micro data from Mumbai can be used to create an accurate time series of movies released in these four languages.

\footnotetext{
25 The censor board provided us these details via various documents.

${ }^{26}$ The Censor Board provided us documents that allow us to calculate which language movies are being certified at which centers. This information is available from 1982 onwards.
} 
These are also languages which are not likely to see dubbed movies. For example, a Hindi movie does not need to be dubbed in any of these languages given the linguistic similarity. These languages also produce substantial number of movies (For example, Marathi was the $6^{\text {th }}$ largest in volume in year 2011). When we compare our micro databased production index for the four selected languages with the linguistic aggregate data provided by the censor board (see footnote 25), it matches quite well, giving us confidence that we have captured the correct production numbers for these movies. We thus construct a movie production series based on movies in these selected languages, which we term "the selected language" series.

Hence, we have four different measures of India's annual movie production. Each of the measures has shortcomings and advantages. Our strategy is to perform our analyses using all four measures, checking whether they deliver consistent results.

Our country-by-year database also includes a proxy for aggregate Indian box office revenue. We unfortunately do not directly observe aggregate box office revenue in India, but we can create a useful proxy from Indian entertainment tax revenue data. All Indian states levy taxes on all sort of entertainment (circus, gambling, concerts, horse racing and so on) including movie exhibition. Until 1990, movie exhibition generated 96-98\% of entertainment tax revenue (See Mittal 1995, page 136 Table 6.5). We have data on entertainment tax revenues for the state of Uttar Pradesh (UP) from 1960 to 1990, compiled from two sources (Mittal 1995, page 126, Table 6.1 and 6.2; and Bagchi, Bajaj and Byrd 1992). UP is the most populous state in India and has a largely Hindi-speaking population, and most Hindi movies are released in the state. The tax levied is a fixed amount per ticket, so the time path of entertainment tax revenue collection reflects Hindi 
movie box office performance over time in the state and provides a potentially

corroborating source of data on box office collections and movie production. ${ }^{27}$

\section{Results}

\subsection{Did Piracy Reduce Appropriability?}

\section{Evidence from Movie-Level Box Office Revenues}

The documentary evidence of section 2 suggests that unauthorized movie consumption from the mid 1980 through the 1990s would have reduced the revenue available to movie production. The ideal test for this would place two movies of equal appeal into the market in, say, 1980 and 1995, years before and during the presumptive appropriability crisis. The question would then be whether the movie released in 1995 generates less revenue than the movie released in 1980. Of course we cannot perform this test. But we can do something similar with our movie-level data set.

We can ask whether conditional on the IMDb user rating (which is a measure of the movie’s appeal to audiences, or “quality”), movies of a given revenue rank earn less in the presumptive piracy years. This approach will work if our quality measure is indeed related to revenue. Column (1) of Table 1 reports a regression of log real box office on the IMDb rating, and the coefficient is positive and highly significant. Only the top 20 movies of each year are included, for comparability across years.

\footnotetext{
${ }^{27}$ Our data include information on the tax rate itself and ticket prices (Mittal 1995). The total price paid by the consumer is the pre-tax price plus tax. Inflation adjusted post tax prices actually dropped in the state over time (see Mittal 1995; Table 3.3 page 76). Figure 3.2 in the book suggests that proportion of tax, on average, went up during 80's. Thus, (i) real tickets prices were declining, (ii) proportion of tax for a given price increased, (iii) population and income of the state were rising. These facts suggest an increase in tax collection if the box office performance of the movies remained stable during 80's and 90's. As we will see, the tax collection actually went down around 1985, suggesting that the movies generated lower box office revenues in the state during the period of interest.
} 
The second column adds year dummies, and the IMDb rating variable remains significant. The year dummies in this specification allow us to ask whether the revenue to a movie of a given quality level varies over time. Figure 1a presents the year dummies from the model in column (2), along with a median band to show trends within the rather variable year effects. Revenue per movie, conditional on IMDb rating, rises from 1960 to 1980, and then falls into the early 1990s. It rises and regains its past peak around 2000.

If we take the period 1985-2000 as the period of piracy, then it is useful to summarize the extent to which revenue in that period fell short of the general trend. We characterize that with a regression of log real revenue on the IMDb rating, a time trend, and a dummy for the period 1985-2000, in column (3). The coefficient on the 1985-2000 indicator is -0.50 (with a standard error of 0.08 ), indicating that revenue was below trend by 50 percent during this period.

The fourth column includes all of the data (adding movies ranked 21-50 for 19812010) and adds revenue rank dummies to the specification in column (2) to account for the fact that we include different numbers of movies from different years. Because of the relationship between revenue and ratings - higher-rated movies also have higher revenue ranks - the rating variable becomes insignificant with the inclusion of rank dummies. Figure $1 \mathrm{~b}$ reports the year dummies from the model in column (4). The year dummies and therefore a measure of appropriability - rise from 1960 to 1970, hold steady from 1970 to 1985 , then fall to a minimum in the early 1990s. Since then they have risen, regaining their past peak shortly after 2000 and continuing to rise since then. Column (5) reports a specification analogous to column (3), producing an estimate of -0.38 (with a standard error of 0.07) for the revenue depression during the piracy period. 
Figures 1a and 1b confirm that during 1985-2000, Indian movies generated less revenue than they had earlier, by 38 or 50 percent, depending on the specification. The timing of this reduction in revenue appropriability matches the timing of the spread of VCR and cable piracy. Given the lack of evidence that the Indian economy was in any significant recession or shrinking otherwise, we take this as evidence that piracy had a substantial negative impact on Indian movie revenue between 1985 and 2000. This variation in the returns to making movies in India sets up our "experiment." We can now ask whether the supply of Indian movies responded to the negative revenue shock.

\subsection{Appropriability and Supply}

\section{Number of New Movies}

Reduced appropriability could affect the production of new motion pictures in various ways. First, reduced revenue opportunities could curtail the number of movies made. Second, lower revenue could reduce the perceived quality of movies produced.

Figure 2 depicts Indian movie production using our four production measures, three from the Indian Censor Board and the other from IMDb. The three CB measures are, (i) censor board aggregate measure that includes dubbed and re-certified movies, (ii) our overall index from the micro data that excludes dubbed movies as identified from the database but has potentially some missing movies, (ii) and our index for selected languages. While the production measures differ in their levels, their trends move together and tell a consistent story. All four series show an increase in the number of films produced from 1960 to 1985. All four exhibit rather sharp decline in production from the 1985 peak until the late 1990s, followed by an increase in production after 2000 . Among the three measures ostensibly covering national movie production, the Censor 
Board aggregate figure is higher in every year, while the IMDb figure is lower. This is expected since IMDb does not include separate entries for dubbed movies. The selected language index is, not surprisingly, below the national measures. The selected language index decline also indicates that the overall decline was just not limited to major languages alone.

In light of the evidence of the previous section's evidence that piracy reduced appropriability, the production decline depicted in Figure 2 provides clear indication that diminished revenue reduced the supply of new movies. Moreover, the two pieces of evidence can be used to generate a rudimentary measure of the supply elasticity. Regressions of the logarithms of our three measures of annual movie production on our two appropriability measures provide simple estimates of the movie supply elasticity. (Note that the appropriability measures are already in logarithms, as they are the year effects from regressions using log revenue as the dependent variable). As Table 2 indicates, the implied supply elasticities vary between 0.14 and 0.78 , and seven of eight of the estimates are statistically significant. The four middle estimates are between 0.5 and 0.7 , as are the mean and median of the estimates.

\subsection{Robustness: Additional Tests}

Before concluding that the post-1985 decline in production was caused by piracy it seems prudent to compare Indian movie production trends with a) general growth in the Indian economy, and b) the time pattern of movie production in other countries. The question is whether the Indian movie production pattern can be explained by factors other than the piracy that we identify. 
Figure 3 compares IMDb Indian movie production with population and GDP growth, using both log and level scales. Population and GDP grow steadily in India between 1960 and 2012, in contrast with the production of movies. The decline in movie production between 1985 and 2000 does not appear to be driven by a contraction in the underlying economy. It is worthwhile to note than the decline in production sustained through the 15 year period. A short term shock cannot explain such a sustained decline.

It is possible that the contraction in Indian movie production reflects changed preferences for movies, or changed costs of making movies, that are not specific to India. If so, then we should see a contraction in movie production in other countries. One might expect the arrival of the VCR to produce a similar impact on appropriability and production in other countries, particularly those with weak intellectual property protection. However, the motion picture industries of many of the large developing nations (such as China and Russia) were government-controlled and financed as the VCR diffused, possibly muting the impact.

Figure 4 compares the IMDb Indian movie production totals with IMDb data for other countries, 1970-2000. Movie production increases steadily in the US, the UK, and France. While other countries exhibit some fluctuations, it does not appear based on international comparison that India's contraction is part of a general demand or supplybased shift away from movie production.

While the number of movies made in India contracted, the number of movies released may provide a misleading measure of investment. It is possible, for example, that producers maintained high investment levels, making fewer but more costly - and presumably more appealing - movies. Unfortunately, we lack data on Indian movie 
investment going back to the 1980s. But we do have direct measures of the appeal of movies to audiences, in the IMDb ratings. If the movies of the 1985-2000 period were made more appealing by higher investment per film, then we should be able to see this in higher IMDb ratings for those movies.

Returning to the movie-level data above (on the top 20 or 50 Hindi movies released each year), we can ask how their IMDb ratings evolve over time. A regression of these movies' IMDb ratings on year dummies gives the annual time pattern in Figure 5. Ratings were stable until 1982-83 and then declined. Ratings rise after 2000. The ratings data show no evidence of an increase in quality offsetting the reduced movie output; instead, the ratings data suggest that not only quantity but also quality fell when revenue was stressed by piracy. Thus, quality-adjusted production fell even more than shown in Figure 2.

\section{Evidence from an Aggregate Box Office Revenue Proxy}

Given the fragmentary nature of the available data, we are interested in further evidence on the evolution of revenue and new products from other possible sources. To this end we examine the time series on entertainment tax revenue in Uttar Pradesh. As we explained in the data section, tax revenue is proportional the box office revenue. Revenue, in turn, depends on the gross-of-tax ticket price, number of tickets sold (number of people watching the movie) and the number of movies made. If the various mechanisms documented above are operative - if revenue has fallen conditional on product quality and the number of movies released falls - then entertainment tax revenue should fall. 
Figure 6 plots the deflated entertainment tax revenues, per capita income of the state, and the population of the state from 1960 to 1990, which is just a few years into the period of piracy that we identify. Entertainment tax revenues rise almost monotonically from 1960 to 1983, then decline steadily to 1990, when revenues are almost 20\% lower than in 1983. The entertainment tax revenue time series corroborates the evidence of reduced revenue and production.

\section{The Indian Supply Responses in Perspective}

It is useful to compare the episode of Indian movie piracy examined in this study with three other contexts in which innovation has affected costs or revenues of media products: 1) digitization and music after 1999, 2) windowing and international distribution of Hollywood movies, 1980-2000, and 3) the effect of new technology on movie making since 2005.

In general these episodes differ by whether the innovation affects revenues, costs,

or both. In the Indian episode, technological change reduced appropriability - weakening effective demand - without any offsetting effect on the cost of bringing new works to market. This stands in rather sharp contrast to the experience of the recorded music industry following digitization. While file sharing substantially weakened effective demand, digitization also reduced the costs of producing, distributing, and promoting new music (Waldfogel, 2013). These cost reductions are big enough that the number of new products brought to market has increased despite the collapse of revenue (Aguiar, DuchBrown, and Waldfogel, 2014).

The effect of a negative revenue shock on the Indian film industry around 1985 also contrasts rather sharply with Hollywood's response to a positive revenue shock 
around 1980. Between 1980 and 2000 Hollywood's real revenue expanded enormously due to windowing as well as the development of export markets (see Waterman, 2005). According to Edward Jay Epstein, the major Hollywood studios' real revenue increased from $\$ 9.2$ billion in 1980 to $\$ 42.9$ billion in 2007 (both in 2007 dollars). ${ }^{28}$ Over roughly the same period, according to Vogel (2007), the number of movies released by the Hollywood majors was essentially stable. Releases averaged about 175 per year between 1980 and 1984, and releases averaged about 205 between 2001 and 2005.

While a 37-50 percent decrease in Indian revenue reduced supply enough to suggest an Indian supply elasticity of roughly 0.5-0.7, a 300 percent increase in US revenue raised supply by about 15 percent, suggesting a US supply elasticity of about 0.05. The differing supply elasticities implied by these two historical episodes suggest at a minimum that the motion picture supply elasticity identified from the Indian piracy episode is not a deep behavioral parameter but instead depends on the industrial context.

Recall that Indian movies tend to be made at low costs and that US movies have much higher costs. It is likely that some part of the input costs for US movies includes rents for scarce inputs (actors, directors). If the payments to inputs for Indian movies were closer to their competitive rates in 1985, then a reduction in revenue would not be borne as a reduction in input prices; it would instead reduce the number of works created.

The number of movies that can be distributed in theaters may also have limited the number of movies that Hollywood studios wish to make each year. If distribution faces a bottleneck, then an increase in demand need not lead to an increase in the number of products made. Instead, the higher demand may manifest itself as higher revenue, prompting suppliers of inputs to bargain for larger payments.

\footnotetext{
${ }^{28}$ http://www.edwardjayepstein.com/MPA2007.htm
} 
It is not clear whether the supply-contracting impact of the negative revenue shock in India in 1985 would be reproduced today in the US, for two reasons. First, costs of film production have fallen substantially since 2005 (Waldfogel, 2014), with the consequence that the number of new independent movies produced in the US has increased by an order of magnitude. While production would be expected to contract in the face of revenue reduction if costs were held constant, costs are now falling. Hence, it is not clear that revenue reduction would effect a supply contraction in the US today.

Second, while some movies - the releases of the major studios - have high production costs, some of these costs are endogenously high precisely because of their high expected revenue. A-list actors are paid \$20 million or more for their participation in major releases. ${ }^{29}$ If the commercial prospects of these movies were dimmed by, say, piracy, it is possible that their production would slow. But it is also possible that producers would negotiate lower payments to the scarce talent, allowing production to continue, albeit with lower payments.

\section{Conclusion}

In the decade and a half since Napster, copyright research has found substantial negative impacts of piracy on revenue. Given the costs of bringing works to market, one might expect evidence of a negative impact of piracy on the supply of products. Yet, such evidence has been elusive. In the music context, substantial cost reductions seem to have offset revenue reductions, leading to net growth in the number of new products as well as their appeal. In this paper, using the experience of the Indian movie industry during the diffusion of VCR and cable piracy, we offer direct evidence of an impact of

\footnotetext{
${ }^{29}$ Tom Hanks was reportedly paid \$50 million for his role in Angels and Demons. See http://www.statisticbrain.com/tom-hanks-career-earnings/ .
} 
piracy on the supply of new products. We find that during the period of widespread unpaid consumption, revenue fell by a third to a half. Over the same period, the number of new products released fell substantially, suggesting a supply elasticity on the order of 0.5-0.7. While our results provide clear evidence that piracy can undermine the creation of new products, a comparison of the Indian context with others shows that the impact of shocks to revenue depends on other facts as well, such as how technological change affects costs.

Our research is particularly relevant for markets like India where empirical research has been severely impeded due to lack of data, despite the industry's prominence. We hope our findings, based on data drawn from disparate sources, will aid Indian policy makers in crafting and enforcing appropriate copyright laws. One important contribution of this paper has been to assemble data sources which have been elusive so far. We hope to foster further research on the supply response to technological change in developing countries and elsewhere. The usual call for more research is well warranted. 


\begin{tabular}{lccccc}
\hline $\begin{array}{l}\text { Table 1: } \\
\text { Quality and } \\
\text { Appropriability }\end{array}$ & $(1)$ & $(2)$ & $(3)$ & $(4)$ & $(5)$ \\
& & & & & \\
& $\begin{array}{l}\text { log real } \\
\text { revenue }\end{array}$ & $\begin{array}{l}\text { log real } \\
\text { revenue }\end{array}$ & $\begin{array}{c}\text { log real } \\
\text { revenue }\end{array}$ & $\begin{array}{c}\text { log real } \\
\text { revenue }\end{array}$ & $\begin{array}{c}\text { log real } \\
\text { revenue }\end{array}$ \\
\hline IMDb rating & 0.1172 & 0.1505 & 0.1635 & -0.0090 & 0.0133 \\
& $(0.0279)^{* *}$ & $(0.0183)^{* *}$ & $(0.0194)^{* *}$ & $(0.0140)$ & $(0.0136)$ \\
$1985-2000$ & & & -0.5043 & & -0.3778 \\
& & & $(0.0764)^{* *}$ & & $(0.0682)^{* *}$ \\
Constant & 17.0946 & 16.2944 & -20.8798 & 18.4951 & -10.8791 \\
& $(0.1979)^{* *}$ & $(0.1317)^{* *}$ & $(5.2268)^{* *}$ & $(0.1291)^{* *}$ & $(5.7973)$ \\
Sample & Top 20 & Top 20 & Top 20 & All & All \\
Rank dummies & No & No & No & Yes & Yes \\
Year dummies & No & Yes & No & Yes & No \\
Time trend & No & No & Yes & No & Yes \\
Observations & 968 & 968 & 968 & 1842 & 1842 \\
R-squared & 0.04 & 0.38 & 0.24 & 0.79 & 0.73 \\
\hline
\end{tabular}

Notes: regressions of log box office revenue for top Hindi movies on IMDb ratings, year dummies, and rank dummies. For 1981-2010 the data include the top 50 movies. Prior to 1981, the data include as few as the top 20 movies per year. Standard errors, clustered on year, in parentheses. * significant at $5 \%$; ** significant at $1 \%$. 
Table 2: Motion Picture Supply Elasticity

\begin{tabular}{|c|c|c|c|c|c|c|c|c|}
\hline & $\begin{array}{c}(1) \\
\log \mathrm{CB} \\
\text { agg films }\end{array}$ & $\begin{array}{c}(2) \\
\text { log CB } \\
\text { movie- } \\
\text { level films }\end{array}$ & $\begin{array}{l}(3) \\
\log \text { IMDb } \\
\text { films }\end{array}$ & $\begin{array}{c}(4) \\
\log C B \\
\text { regional }\end{array}$ & $\begin{array}{c}(5) \\
\log \mathrm{CB} \\
\text { agg films }\end{array}$ & $\begin{array}{c}(6) \\
\text { log CB } \\
\text { movie- } \\
\text { level films }\end{array}$ & $\begin{array}{l}\text { (7) } \\
\log \text { IMDb } \\
\text { films }\end{array}$ & $\begin{array}{c}(8) \\
\log C B \\
\text { regional }\end{array}$ \\
\hline Appropriability 2 & & & & & $\begin{array}{c}0.5816 \\
(0.1613)^{* *}\end{array}$ & $\begin{array}{c}0.7007 \\
(0.1479)^{* *}\end{array}$ & $\begin{array}{c}0.2264 \\
(0.1098)^{*}\end{array}$ & $\begin{array}{c}0.7875 \\
(0.2001)^{* *}\end{array}$ \\
\hline Observations & 50 & 50 & 50 & 49 & 50 & 50 & 50 & 49 \\
\hline R-squared & 0.20 & 0.33 & 0.04 & 0.24 & 0.21 & 0.32 & 0.08 & 0.25 \\
\hline
\end{tabular}

Notes: Regressions of log Indian film production measures on our appropriability measures. “Appropriability 1” and "appropriability 2” are derived from columns (2) and (4) of Table 1, respectively. Standard errors in parentheses.* significant at 5\%; ** significant at 1\% 
Figures $1 \mathrm{a}$ and $1 \mathrm{~b}$

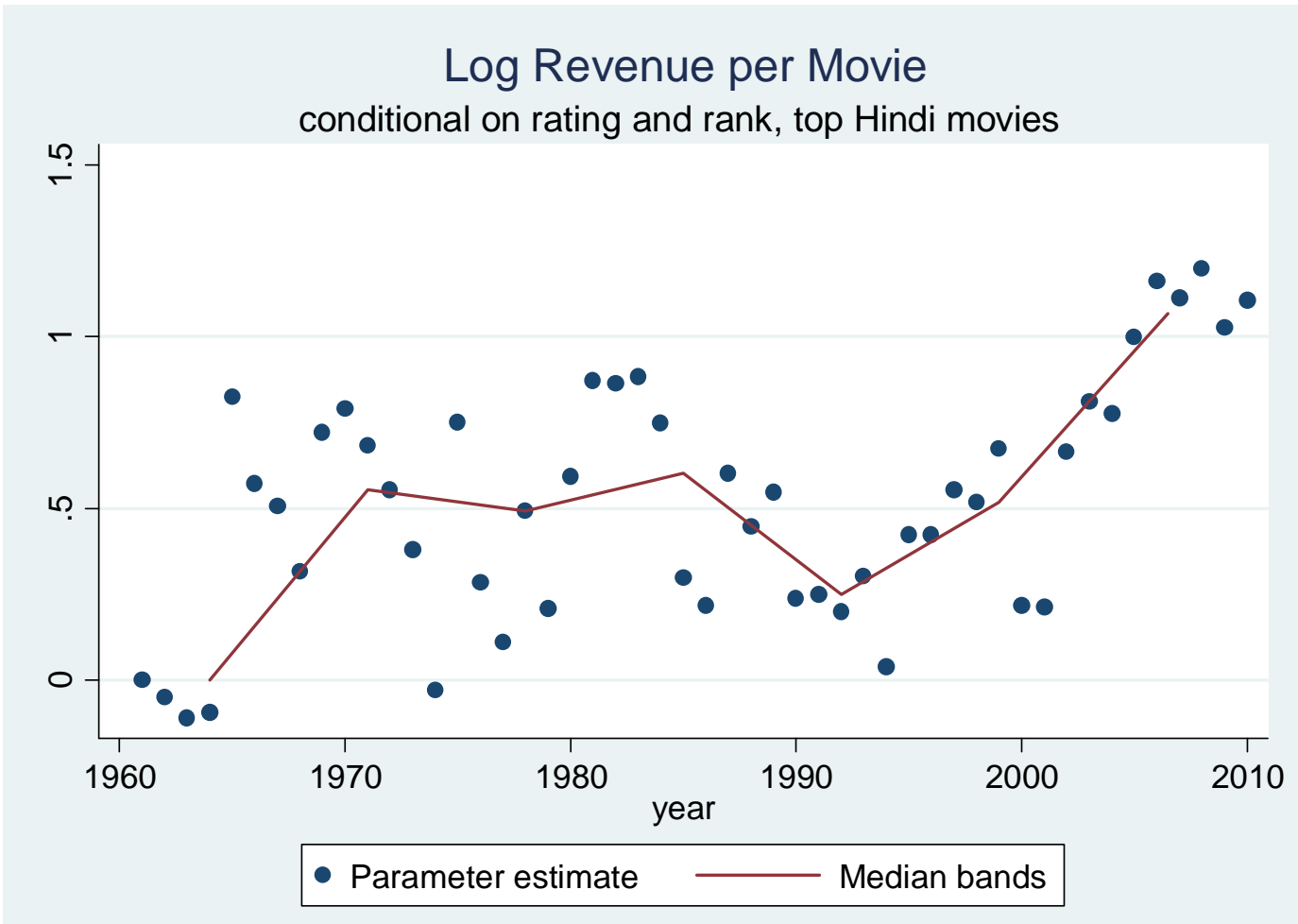

Log Revenue per Movie

conditional on rating, top 20 Hindi movies

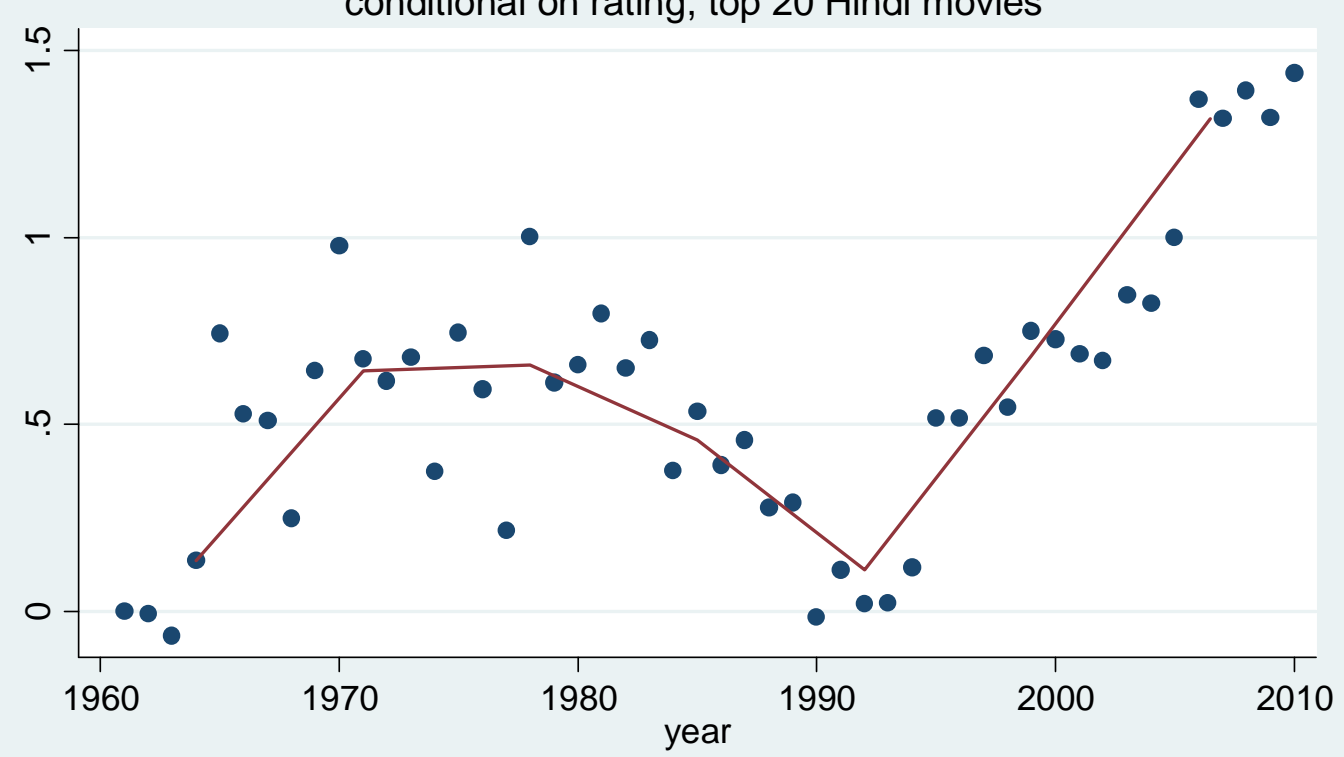

- Parameter estimate Median bands 
Figure 2: Indian Movie Production
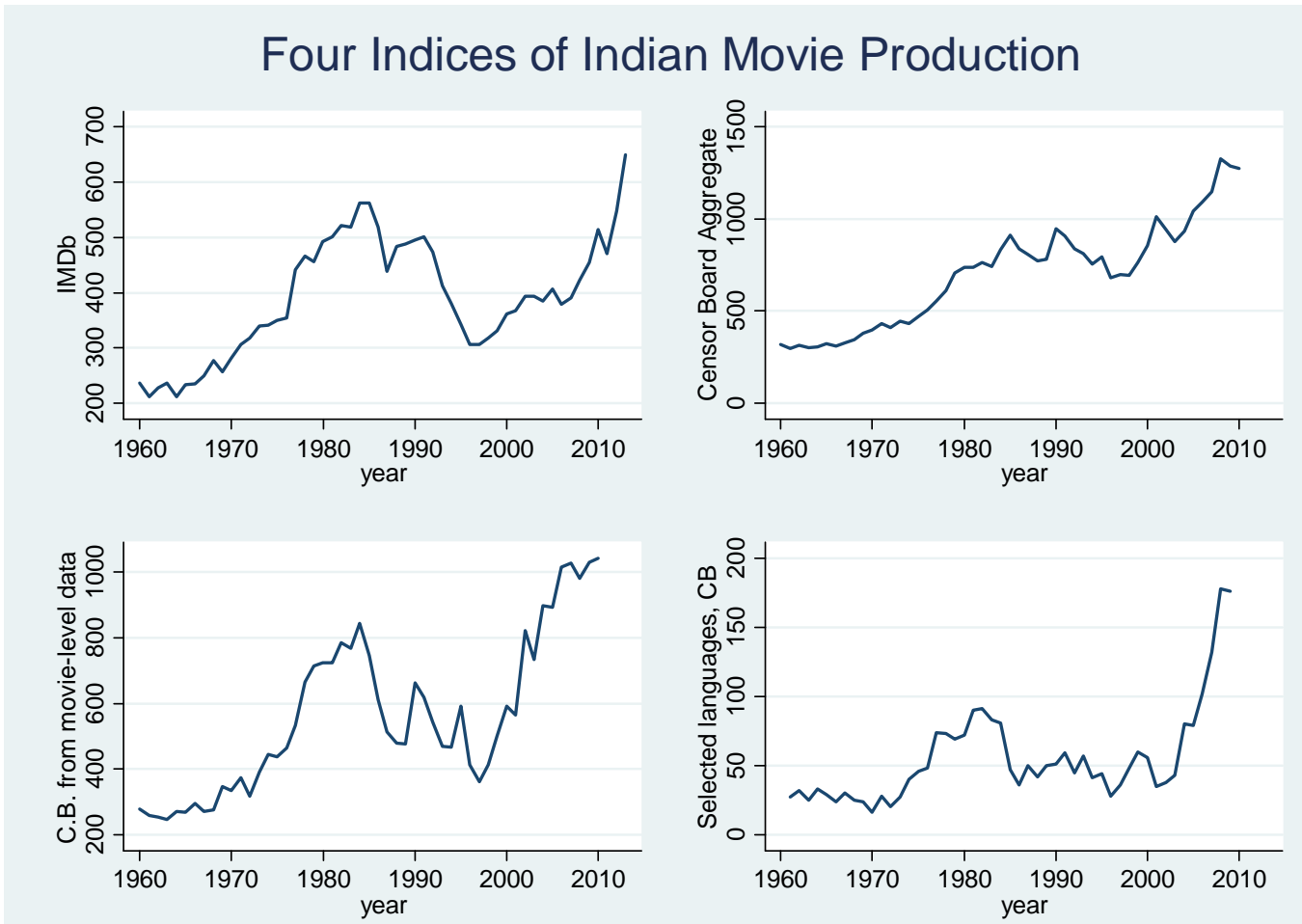
Figure 3: IMDb Indian Movies, Population, and GDP

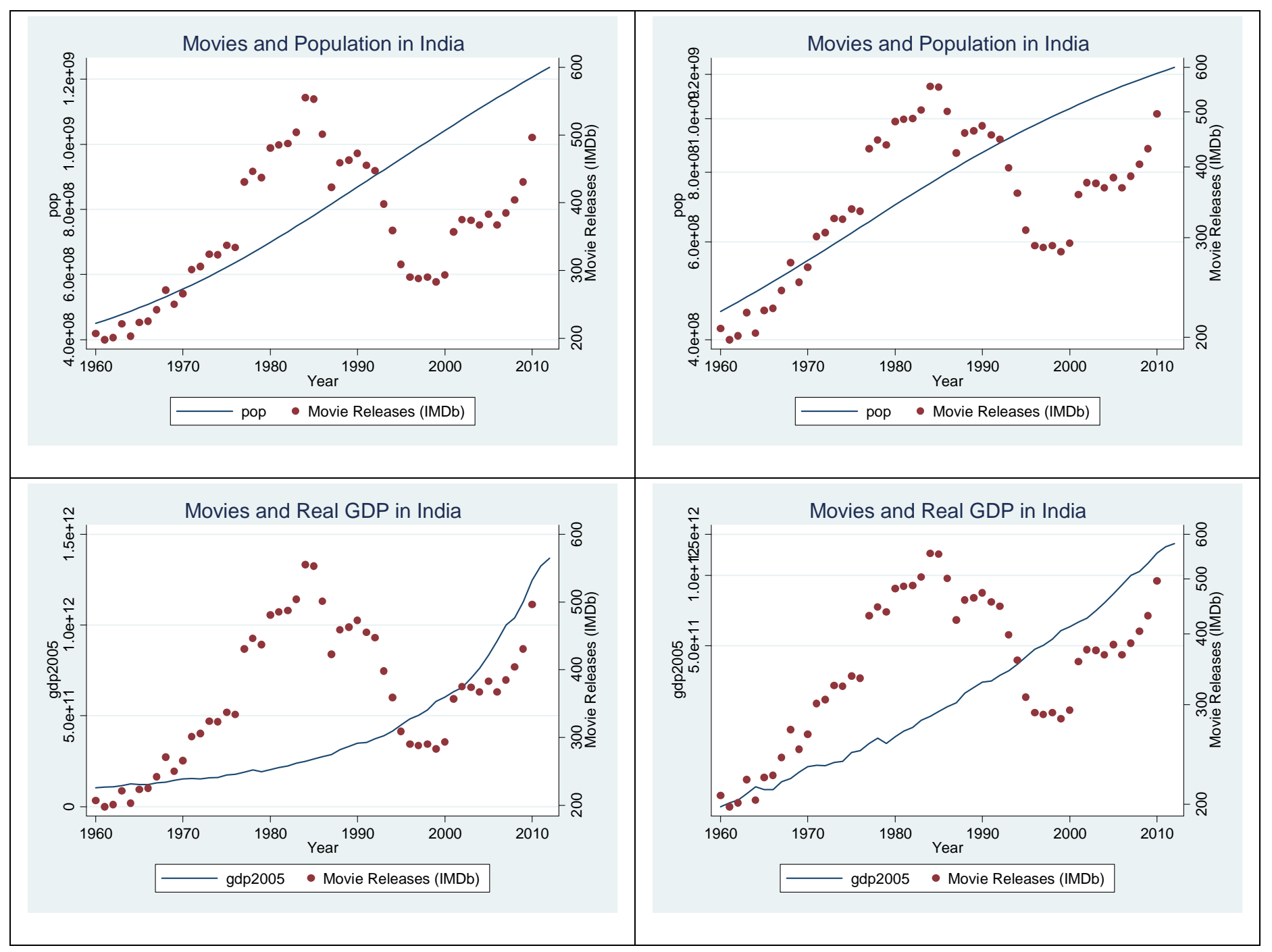


Figure 4: Indian Production vs Other Countries

\section{Film Production in Various Countries Compared with India}
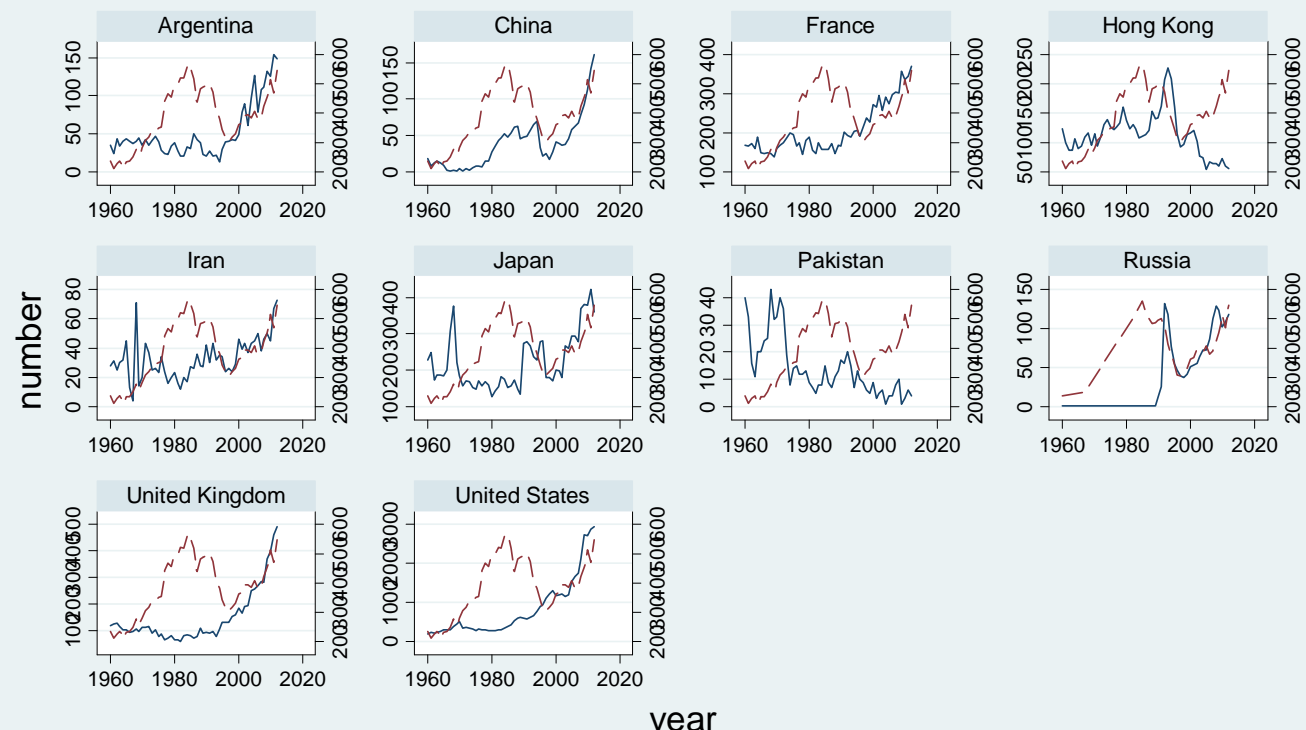

Graphs by country 
Figure 5: Ratings over Time

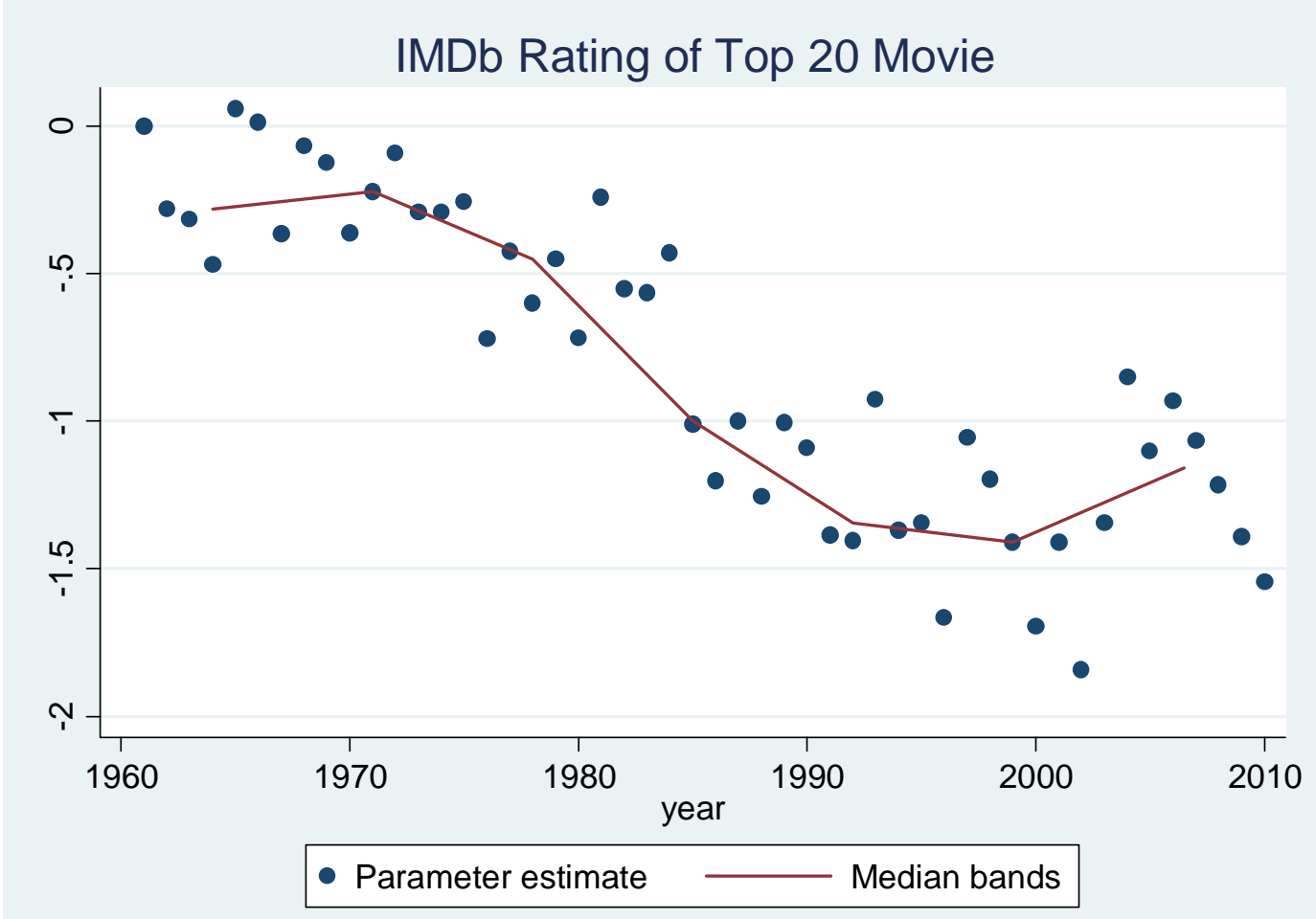


Figure 6: Entertainment Tax from the state of UP

— Ent Tax in (Rs Crore)

_- Population (in 10 million)

— Per Capita Income (in Rs)

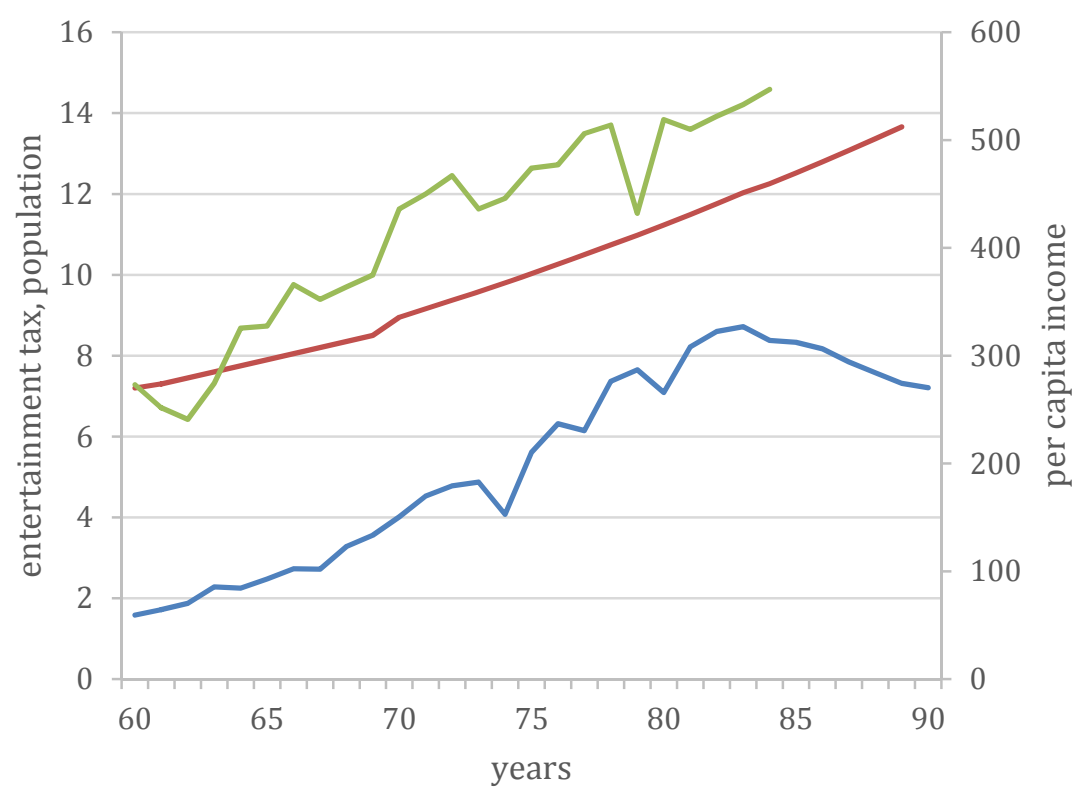




\section{References}

Alvarado ed. Manuel, 1988. Video World Wide, UNESCO and John Libbey. London.

Aguiar Luis, Nestor Duch-Brown, and Joel Waldfogel. “The Flow of New Recorded Music Products since Napster: A Transatlantic Perspective” EC Joint Research Center IPTS, 2014.

Boyd Douglas, Joseph Straubhaar, John Lent (1989), VideoCassette Recorders in the Third World. Longman Inc.

Buccafusco, Christopher J. and Heald, Paul J., Do Bad Things Happen When Works Enter the Public Domain?: Empirical Tests of Copyright Term Extension (August 15, 2012). Berkeley Technology Law Journal, Forthcoming; Chicago-Kent College of Law Research Paper No. 2012-04. Available at SSRN:http://ssrn.com/abstract=2130008 or http://dx.doi.org/10.2139/ssrn.2130008.

D’Souza 1991. Video rental shops in India hurt by Cable Shenanigans, Billboard, Nov 23, p 10.

Danaher, Brett, Michael D. Smith, Rahul Telang. 2014. Piracy and Copyright Enforcement Mechanisms, Lerner and Stern, eds. Innovation Policy and the Economy, Volume 14. University of Chicago Press, Chicago, Illinois.

(http://ssrn.com/abstract=2273716)

Heald, Paul J. 2013. How Copyright Keeps Works Disappeared (July 5). Illinois Program in Law, Behavior and Social Science Paper No. LBSS14-07; Illinois Public Law Research Paper No. 13-54. Available at SSRN:http://ssrn.com/abstract=2290181 or http://dx.doi.org/10.2139/ssrn.2290181

Handke, Christian, 2012. "Digital copying and the supply of sound recordings," Information Economics and Policy, Elsevier, vol. 24(1), pages 15-29.

IIPI (2001), International Intellectual Property Alliance, 2001, SPECIAL 301 REPORT, INDIA

Kohli-Khandekar Vanita, 2013. The Indian Media Business, Fourth Edition, Sage publications Pvt Limited.

Liebowitz, Stan J., The Metric is the Message: How Much of the Decline in Sound Recording Sales is Due to File-Sharing? (November 2011). Available at SSRN: http://ssrn.com/abstract=1932518 or http://dx.doi.org/10.2139/ssrn.1932518

Mittal Ashok, 1995. Cinema Industry in India: Pricing and Taxation. Indus Publishing Company, New Delhi. 
Bagchi Amaresh, J. L. Bajaj, William A Byrd. 1993, State Finances in India. Vikas Publication.

Moullier Bertrand, 2007. Whither Bollywood? IP Rights, innovation and economic growth in India’s film industries. George Washington University Law School.

National Research Council. Copyright in the Digital Era: Building Evidence for Policy. Washington, DC: The National Academies Press, 2013.

Oberholzer-Gee Felix \& Koleman Strumpf, 2007. "The Effect of File Sharing on Record Sales: An Empirical Analysis," Journal of Political Economy, University of Chicago Press, vol. 115, pages 1-42.

Oberholzer-Gee Felix \& Koleman Strumpf, 2010. "File Sharing and Copyright," NBER Chapters, in: Innovation Policy and the Economy, Volume 10, pages 19-55

National Bureau of Economic Research, Inc.

O’Regan Tom. 1991. From piracy to sovereignty: international VCR trends. The Australian Journal of Media \& Culture, 4 (2).

Rob, Rafael \& Waldfogel, Joel, 2006. "Piracy on the High C's: Music Downloading, Sales Displacement, and Social Welfare in a Sample of College Students," Journal of Law and Economics, University of Chicago Press, vol. 49(1), pages 29-62, April.

Vogel Harold, 2007. Entertainment Industry Economics, 7th edition. Cambridge: Cambridge University Press, 2007.

Joel Waldfogel, 2012. "Copyright Protection, Technological Change, and the Quality of New Products: Evidence from Recorded Music since Napster," Journal of Law and Economics, University of Chicago Press, vol. 55(4), pages 715 - 740.

Waldfogel Joel 2014. "Digitization and the Quality of New Media Products: The Case of Music," in Economics of Digitization, University of Chicago Press, Avi Goldfarb, Shane Greenstein, and Catherine Tucker, eds.

Waldfogel Joel. 2014. Cinematic Explosion: Movies, Gatekeepers, and Product Discovery in the Digital Era. Unpublished Paper, University of Minnesota.

Waterman David, 2005. Hollywood's road to riches. Cambridge, Mass. : Harvard University Press, 2005

Screen Digest, 1998. Bollywood on Strike to Protest against Piracy. September 1.

Study on Copyright Piracy in India (The SCP study) 1999. Ministry of Human Resource Development, Government of India. 